\title{
A goal programming model for selecting a facility location site
}

Revue française d'automatique, d'informatique et de recherche opérationnelle. Recherche opérationnelle, tome 19, n 1 (1985), p. 1-14.

<http://www.numdam.org/item?id=RO_1985_19_1_1_0>

(C) AFCET, 1985, tous droits réservés.

L'accès aux archives de la revue « Revue française d'automatique, d'informatique et de recherche opérationnelle. Recherche opérationnelle » implique l'accord avec les conditions générales d'utilisation (http://www.numdam.org/ legal.php). Toute utilisation commerciale ou impression systématique est constitutive d'une infraction pénale. Toute copie ou impression de ce fichier doit contenir la présente mention de copyright.

\section{Numdam}

Article numérisé dans le cadre du programme

Numérisation de documents anciens mathématiques

http://www.numdam.org/ 


\title{
A GOAL PROGRAMMING MODEL FOR SELECTING A FACILITY LOCATION SITE (*)
}

\author{
by N. K. Kwak $\left({ }^{1}\right)$ and Marc. J. SchniederJans $\left({ }^{2}\right)$
}

\begin{abstract}
This paper presents a generalized goal programming model for a facility location analysis which considers a simultaneous conversion of productive resources. The model includes four of the most common objective factors for selecting a facility location site. It was applied to a site location problem solution for an American Midwestern food processing manufacturer. This model helps facilitate decision-making and planning by providing management information.
\end{abstract}

Keywords: Koal programming; facility location analysis

Résumé. - Cet article présente un modèle de "goal programming " généralisé pour l'analyse de la localisation d'un service, où l'on considère une conversion simultanée de ressources productives. Le modèle comprend quatre des critères les plus courants pour la sélection d'un site pour y localiser un service. Il a été appliqué à la résolution du problème de localisation d'un site pour une manufacture de produits alimentaires du "Middle West " américain. Ce modèle aide la prise de décision et la planification en procurant des informations de gestion.

\section{INTRODUCTION}

The objective factor analysis consists usually of a comparison of the budget cost of the new facility in a selected location and the costs of the objective factors at each of the potential sites. Unfortunately, many existing comparative techniques tend to focus on only one objective factor at a time $[2,7$, and 9]. For example, the use of the transportation method for comparing transportation costs between sites is appropriate when transportation costs are the dominating objective criterion for determining a site. However, it is only part of the solution when other factors are equally as important as transportation cost. Still other multiobjective site location models, view each

(*) Received on March 1983.

(1) Saint Louis University, 3674 Lindell bd, Saint Louis, Missouri 63108, U.S.A.

R.A.I.R.O. Recherche opérationnelle/Operations Research, 0399-0559/85/01 14/\$3.40

(C) AFCET-Gauthier-Villars. 
objective factor as a separate goal to be achieved in accordance with some ranking or prioritization system [5] and [6].

These analyses overlook the possibilities that objective factors may have simultaneous conversion characteristics. These conversion characteristics exist in the decision environment due to availability of multiple production processes that utilize resources at different rates. They may also exist because of trade-offs at differentiable units of a resource (or resources) may arise. A trade-off between material utilization and labor may arise due to the inefficiencies of skilled vs. unskilled workers in utilizing material and possible material scrap. The purpose of this paper is to present a generalized goal programming model for a facility location analysis that will consider a simultaneous conversion of resources. Specifically, this model will concern itself with the analysis of four major objective factors (i. e., labor, materials, utilities, and transportation costs) that are frequently examined at the site selection stage of the facility location analysis. Other objective factors such as land cost, construction costs and taxes do not as obviously possess variables that can interact with the other objective factors. Therefore, they are excluded from the model presented (but not from the site location analysis).

The major advantage of the proposed goal programming model presented in this paper is that it takes these various objective factors into consideration simultaneously and permits resource trade-offs to be considered. Prior facility location site selection models have not permitted such simultaneous objective factor analysis. Also, the goal programming model provides useful post-site selection operations planning information.

In order to illustrate the use of the model, a real problem situation comparing alternative site locations will be presented.

\section{MODEL FORMULATION}

\section{Background}

The generalized model presented in Appendix 1 was utilized to solve a site location problem for a regional food processing manufacturer based on its operational data $\left({ }^{3}\right)$. The manufacturer produces food items for catering companies in the eastern region of the country. The manufacturing company

$\left({ }^{2}\right)$ University of Nebraska-Lincoln.

$\left(^{3}\right)$ By request of the company officers, the name of the manufacturer is to be anonymous.

R.A.I.R.O. Recherche opérationnelle/Operations Research 
decided to expand operations into the Midwestern region of the U.S.A. The expansion entailed the building of a new manufacturing plant/warehouse to be added to the firm's existing five plant/warehouse facilities. The company's marketing research department performed the first three stages of the comprenhensive facility location analysis. The results of their analysis defined two potential site locations for the future manufacturing plant. Site $A$ was located 50 miles west of the St. Louis City area. Site $B$ was located just outside the eastern boundary of East St. Louis, Illinois. The 70 miles between these two locations result in a number of unique conditions that had to be considered in the fourth (i.e., site location) stage of the facility location analysis.

In utilizing the goal programming model to aid in the site location stage of the analysis, the goal constaints for both site locations needed to be formulated. To reduce redundancy and hopefully enhance understanding of the model, only select constraints for both sites will be presented.

\section{Variable Definitions}

The proposed goal programming model not only provides information on the site selection decision, but also gives very useful production/operations planning information. Specifically, the model defines the optimal unit usage of resources such as labor, materials and utility usage. Additional operations information includes a shipping schedule of finished goods from plant to warehouse. In the case of our food processing manufacturer example, the decision variable definitions are presented in Table $\mathbf{I}$.

\section{Goal Constraints}

There are six priority levels in the proposed goal programming model for site location. As listed by constraint in Appendix 1, they are; definition of problem, conversion of resources, minimization of budgeted labor costs, minimization of budgeted material costs, minimization of budgeted utilities costs, and minimization of budgeted transportation costs. Within each of these priority levels, there are numerous sub-goals and objectives that will vary from application to application. In the case of our food processing manufacturer example, each goal constraint will be presented, by priority level as defined in Table II.

$P_{1}$ : Definition of Problem. - The definition of the food processor problem contains three types of problem requirements: resource usage, supply/demand requirement and finished product requirements. The generalized goal constraint expressions used to model these requirements are presented in Equations (2), (3), (4) and (5) in Appendix 1. 
TABLE I

Variable Definition and Optimal Values for Both Site Locations.

\begin{tabular}{|c|c|c|c|}
\hline Variables & Description & $\begin{array}{c}\text { Optimal } \\
\qquad A\end{array}$ & $\begin{array}{c}\text { Values } \\
\text { for Sites: } \\
\qquad B\end{array}$ \\
\hline 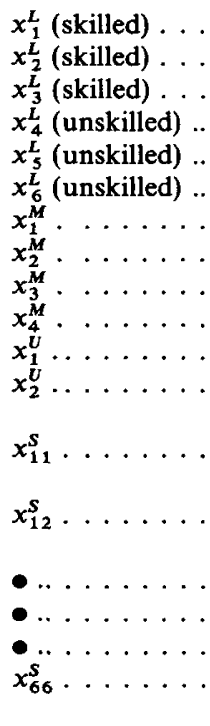 & $\begin{array}{c}\text { Number of category } 1 \text { skilled laborers } \\
\text { Number of category } 2 \text { skilled laborers } \\
\text { Number of category } 3 \text { skilled laborers } \\
\text { Number of category } 1 \text { unskilled laborers } \\
\text { Number of category } 2 \text { unskilled laborers } \\
\text { Number of category } 3 \text { unskilled laborers } \\
\text { Number of units of material } 1 \text { required } \\
\text { Number of units of material } 2 \text { required } \\
\text { Number of units of material } 3 \text { required } \\
\text { Number of units of material } 4 \text { required } \\
\text { Number of units (tons) of coal required } \\
\text { Number of units (1000 cu.ft.) } \\
\text { of gas required } \\
\text { Finished products shipped } \\
\text { from plant } 1 \text { to warehouse } 1 \\
\text { Finished products shipped } \\
\text { from plant } 1 \text { to warehouse } 2 \\
\bullet \\
\bullet \\
\bullet \\
\text { Finished products shipped } \\
\text { from plant } 6 \text { to warehouse } 6\end{array}$ & $\begin{array}{r}18 \\
10 \\
8 \\
38 \\
17 \\
8 \\
8,753 \\
2,240 \\
6,484 \\
5,985 \\
42 \\
288,000 \\
0 \\
10,300 \\
0 \\
\bullet \\
\bullet \\
\end{array}$ & $\begin{array}{r}25 \\
14 \\
10 \\
36 \\
15 \\
5 \\
8,700 \\
2,120 \\
6,280 \\
5,920 \\
42 \\
288,000 \\
0 \\
10,300 \\
0 \\
\bullet \\
\bullet \\
\bullet\end{array}$ \\
\hline
\end{tabular}

Equation (2) in Appendix 1 sets out minimum requirements for labor, materials and utility usage. Site $A$ fell outside labor union spear of influence, while Site $B$ was within labor union influence. The unions in this industry dictated a higher level of labor coverage on the food equipment used in this plant than what was defined as necessary by the equipment manufacturer. Thus, Site $B$ had a higher minimum number of laborers, $b_{i}^{L}$, than those contraints used in formulating the Site $A$ situation. For example, some of the goal constraints for Site $B$ are expressed as follows:

$$
\begin{gathered}
x_{1}^{L}+d_{k}^{L-}-d_{k}^{L+}=25, \\
x_{1}^{L}+x_{2}^{L}+x_{3}^{L}+d^{L-}-d^{L+}=65 .
\end{gathered}
$$

The right-hand-side (RHS) of 25 in the first goal constraint represents the minimum number of category 1 skilled laborers required by union contract

R.A.I.R.O. Recherche opérationnelle/Operations Research 
TABleau II

Priority Analysis for Both Site Locations

\begin{tabular}{|c|c|c|c|c|}
\hline \multirow{2}{*}{ Priority } & \multirow{2}{*}{ Goals } & \multicolumn{2}{|c|}{$\begin{array}{l}\text { Goal Achievement } \\
\text { For Site: }\end{array}$} & \multirow{2}{*}{ Interpretation } \\
\hline & & $A$ & $B$ & \\
\hline$P_{1}$. & $\begin{array}{l}\text { Definition } \\
\text { of Problem }\end{array}$ & 0 & 0 & $\begin{array}{l}\text { The problem solution for either site did } \\
\text { not vary outside the minimum and } \\
\text { maximum parameters established on } \\
\text { the decision variables in the model. } \\
\text { Thus, the solution does not violate } \\
\text { any minimum requirement or } \\
\text { capacity needs in the areas of labor, } \\
\text { materials, utilities, transportation } \\
\text { and production levels. }\end{array}$ \\
\hline$P_{2}$ & $\begin{array}{l}\text { Conversion } \\
\text { of Resources }\end{array}$ & $39.7\left(^{b}\right)$ & 0 & $\begin{array}{l}\text { The positive value for site } A \text { reflects } \\
\text { that complete conversion of resour- } \\
\text { ces was not possible. Values at this } \\
\text { priority name little informational } \\
\text { value for management decisicn } \\
\text { making. }\end{array}$ \\
\hline$P_{3}$ & $\begin{array}{l}\text { Min. Budgeted } \\
\text { Labor Costs }\end{array}$ & $\$ 27,600\left(^{a}\right)$ & $\$ 3,800\left(^{b}\right)$ & $\begin{array}{l}\text { The negative deviation of } \$ 27,600 \text { for } \\
\text { Site } A \text { represents a significant reduc- } \\
\text { tion in budgeted labor costs over the } \\
\text { Site } B \text {. In fact the } \$ 3,800 \text { indicated } \\
\text { Site } B \text { 's labor costs run over budget. }\end{array}$ \\
\hline$P_{4}$ & $\begin{array}{l}\text { Min. Budgeted } \\
\text { Materials Costs }\end{array}$ & $\$ 1,585\left({ }^{b}\right)$ & $\$ 102\left(^{a}\right)$ & $\begin{array}{l}\text { The positive deviation of } \$ 1,585 \text { for } \\
\text { Site } A \text { represents an increase in mat- } \\
\text { erials cost over budget while Site } B \\
\text { showed an under-budget estimate of } \\
\$ 102 \text {. }\end{array}$ \\
\hline$P_{5}$. & $\begin{array}{l}\text { Min. Budgeted } \\
\text { Utilities Costs }\end{array}$ & \& $2,475\left(^{a}\right)$ & $\$ 2,475\left(^{a}\right)$ & $\begin{array}{l}\text { Both sites show a negative deviation of } \\
\$ 2,475 \text { from budgeted utilities costs. }\end{array}$ \\
\hline$P_{6}$ & $\begin{array}{l}\text { Min. Budgeted } \\
\text { Transportation Costs }\end{array}$ & $\$ 4,510\left(^{b}\right)$ & $\$ 4,510\left(^{b}\right)$ & $\begin{array}{l}\text { Both sites show a positive deviation of } \\
\$ 4,510 \text { from budgeted transporta- } \\
\text { tion costs. }\end{array}$ \\
\hline
\end{tabular}

$\left({ }^{a}\right)$ Under-achievement of goal (negative deviation from RHS).

(b) Over-achievement of goal (positive deviation from RHS).

in the processing plant. The second goal constraint models the capacity restriction on the 65 total skilled laborers (i. e., categories 1,2 , and 3) that the plant's capacity will permit. This constraint is expressed in the generalized model in Appendix 1, Equation (3). Similar goal constraints are necessary for the other resource usage requirements of material and utilities usage for both sites.

vol. $19, \mathrm{n}^{\circ} 1$, février 1985 
The supply/demand requirements used to define the problem conform to the classic transportation type problem but in a goal programming format [4, 8]. Equations (4) and (5) in Appendix 1 allow for the transportation cost between the old network of five plant/warehouse facilities and the new facility to be examined. By reseraching truck mileage charts for each of the five plant/warehouse and Site $A$, a transportation problem was formulated depicting average loads shipped (forecasted for Site $A$ ) over a weekly period between the facilities. For example, a supply and demand requirement goal constraints for Site $A$ are expressed as follows:

$$
\begin{aligned}
& x_{11}^{S}+x_{12}^{S}+x_{13}^{S}+x_{14}^{S}+x_{15}^{S}+x_{16}^{S}+d_{i}^{S-}-d_{i}^{S+}=10,300 \\
& x_{11}^{D}+x_{21}^{D}+x_{31}^{D}+x_{41}^{D}+x_{51}^{D}+x_{61}^{D}+d_{j}^{D-}-d_{j}^{D+}=9,000 .
\end{aligned}
$$

The RHS of 10,300 represents the total finished units of product that can be supplied from the six plants (i. e., including the new possible plant of Site $A$ ). The RHS of 9,000 in the second goal constraint represents the forecasted unit demand at each of the existing six warehouses. A total of six goal constraints were required to model the supply side of the transportation problem and six more constraints to model the demand side of the problem. Similarly, a transportation problem was formulated into goal constraints for Site $B$.

To finish the definition of the problem at the $P_{1}$ priority level, a set of goal constraints are required to insure the same finished product production level, $b_{\alpha}^{\pi}$, for each of the $Q$ products produced in the plants. Equation (6) in Appendix 1, states that the sum of the proportional amount of $K$ different types of resources will generate the required quantity of $\alpha$-th type of product.

Equation (6) requires the same number of each of the $\alpha$ different products to be produced at the plant. Since this plant was to be designed to produce 11 different products, this set of 11 constraints would be the same for either Site $A$ or $B$. For example, one goal constraint used to model Site $A$ 's production of a meat product is as follows:

$$
.005 x_{1}^{L}+1.1 x_{2}^{M}+.05 x_{3}^{M}+.0004 x_{2}^{U}+d_{\alpha}^{n-}-d_{\alpha}^{\pi+}=1,500 .
$$

The RHS value of 1,500 represents the desire to produce 1500 units of the specific $\alpha$ product. The resources required to produce a single unit of the $\alpha$ product are .005 units of category 1 skilled laborers, 1.1 units of material 2, .05 units of material 3 and .0004 units of gas. These resource usage coefficients were obtained by researching existing production operations in the other plants. 
$P_{2}$ : Conversion of Resources. - The second priority is assigned to the goal of achieving optimal trade-offs between substitutable resources in production, allowing the opportunity of resource conversion in the final solution. The generalized goal constraint for this priority is presented in Equation (7) in Appendix 1. Specifically, the product of the productivity coefficient of substitutable resources, $c_{k^{\prime}}^{c}$, and the various amount of any $k^{\prime}$-th type of resource is subtracted from the amount of the corresponding $k$-th resource. The result creates a balancing effect on the resulting optimal resource value of $x_{k}^{\rho}$ and $x_{k^{\prime}}^{\rho}$. The productivity coefficient, $c_{k^{\prime}}^{c}$ may have an objective or subjective source. The estimated energy output coefficient difference in various grades of coal is an example of an objective source. An example of a subjective source for the coefficient is the judged productivity difference between skilled and unskilled labor. Also, the productivity coefficient may be used in conjunction with the $r_{k}$ proportion when developing constraints for trade-offs between resources.

Equation (7) in the generalized model in Appendix 1, alows the food manufacturer to include in the site location models relevant information on trade-offs that exist between substitutable resources. In the case of Site $A$, the lack of union influence allows the manufacturer to hire more unskilled labor at a cost of only $82 \%$ of that of skilled labor. Skilled and unskilled labor divided into three job categories represented $83 \%$ of the non-management employment at the processing plant. A constraint was formulated for each of three job categories by letting $x_{k}^{p}$, represent the number of skilled workers to employ, $x_{k^{\prime}}^{p}$, the number of unskilled workers to employ, and $c_{k^{\prime}}^{c}$ equal .82 , representing the productivity coefficient. The set of conversion constraints for each of the three job categories is as follows:

$$
x_{k}^{L}-.82 x_{k^{\prime}}^{L}+d_{k}^{c-}-d_{k}^{c+}=0, \quad k=1,2,3 ; \quad k^{\prime}=4,5,6 .
$$

An additional conflicting constraint was required to reflect the potential trade-off of lower productivity if more unskilled labor were obtained. Inhouse time studies has revealed a $12.5 \%$ average difference in productivity between skilled (productivity $=100$ ) and unskilled (productivity $=87.5$ ) workers. The sets of conversion constraints for each of the three job categories can be expressed as:

$$
x_{k}^{L}-.875 x_{k^{\prime}}^{L}+d_{k}^{c-}-d_{k}^{c+}=0, \quad k^{\prime}=1,2,3 ; \quad k=4,5,6 .
$$

A third conversion constraint was necessary to consider the increase in material's waste due to an increase in unskilled workers. Weekly assessments on material waste (primarily for food stuffs) by skilled and unskilled workers, 
showed a net waste constribution per unskilled worker of .01 of total materials used. This increase in food stuff wastage by unskilled workers can be expressed as a set of conversion constraints as follows:

$$
r_{k} x_{k}^{L}-.99 r_{k} x_{k}^{M}=0, \quad k=1,2,3,4 .
$$

The $r_{k}$ values are included in the expression above to allow the different resources to equate to one another. Since $r_{k} x_{k}^{L}$ must equal $r_{k} x_{k}^{M}$ (both equating to the number of products to produce, $b_{\alpha}^{\pi}$, the above expression forces an increase (of .01 units) in the total amount of materials for an increase in the number of unskilled workers employed. Since three conversions were only possible for Site $A$, only Site $A$ 's model would have these 10 constraints.

Both Sites $A$ and $B$ additionally could substitute the use of coal to power their heating equipment in place of gas. The equipment is capable of utilizing either fuel on an individual daily basis. To determine how many units of each type of fuel was to be used, a goal constraint was structured similar to Equation (7). The productivity coefficient was developed based on the equipment manufacturer's research on uses of the two fuels and local cost factors.

$P_{3}$ : Minimize Budgeted Labor Costs. - Equation (8) in Appendix 1, is associated with the third, fourth, and fifth priorities. It compares the actual cost in each of the three resource areas with the budgeted cost expected in each area. For example, the sum of the cost per unit for each $k$-th type of labor $\left(C_{k}^{L}\right)$ times the amount of the same labor required $\left(x_{k}^{L}\right)$ is compared with the total budget for labor $\left(B^{L}\right)$. In our meat processing example, the following goal constraint was used:

$865 x_{1}^{L}+800 x_{2}^{L}+740 x_{3}^{L}+430 x_{4}^{L}+380 x_{5}^{L}$

$$
+340 x_{6}^{L}+d_{g}^{B(L)-}-d_{g}^{B(L)+}=82,610 .
$$

The RHS value of 82,610 represents the total dollar labor budget cost estimate for the weekly planning horizon. The cost coefficients of $865, \ldots$, and 340 represent the weekly cost of each category of skilled and unskilled laborers. These coefficients were obtained from weekly average wage data.

$P_{4}$ : Minimize Budgeted Material Costs. - Similar to the goal constraint of $P_{3}$, the material cost goal constraint for Site $A$ is expressed as follows:

$$
.36 x_{1}^{M}+.54 x_{2}^{M}+.64 x_{3}^{M}+.72 x_{4}^{M}+d_{g}^{B(M)-}-d_{g}^{B(M)+}=11,235 .
$$

The RHS value of 11,235 represents the total dollar material budget cost estimate for the weekly planning horizon. The cost coefficients of $.36, .54$, 64 and .72 are the cost per unit of each of the meat products used to 
manufacture the finished meat products. The cost coefficients were obtained from routinely collected cost accounting data.

$P_{5}$ : Minimize Budgeted Utilities Costs. - Again using Equation (8) in Appendix 1, the utilities cost goal constraint for Site $\boldsymbol{A}$ is expressed as follows:

$$
147 x_{1}^{U}+.05 x_{2}^{U}+d_{g}^{B(U)-}-d_{g}^{B(U)+}=23,049 .
$$

The THS value of 23,049 represents the total dollar utilities budget cost estimate for the weekly planning horizon. The cost coefficients of 147 and .05 are the cost per unit of coal and gas, respectively.

$P_{6}$ : Minimize Budgeted Transportation Costs. - The sixth priority is represented by Equation (9) in Appendix 1. This equation states that the total transportation cost of supplying the product from the $\mathrm{i}$-th supply sources to the $j$-th demand destinations equals the budgeted transportation cost. The deviational variables represent the difference between the actual and budgeted costs. Consistent with usual transportation problem modeling, the $x_{i j}^{D}$ and $x_{i j}^{S}$ are actually the same variable and so only $x_{i j}^{S}$ is needed in the goal constraint. The goal constraint modeling the food processing problem for Site $A$ is expressed as follows:

$$
.055 x_{11}^{S}+.073 x_{12}^{S}+\ldots+.042 x_{66}^{S}+d_{i}^{T-}-d_{i}^{T+}=58,000 .
$$

The RHS value of 58,000 represents the total dollar transportation budget cost estimate for the weekly planning horizon. The cost coefficients of .055 , $.073, \ldots, .042$ are the cost per unit to transport the supply of finished products from the plants to the warehouses.

\section{Objective Function}

The objective function for facility location site selection model is represented by Equation (1), in Appendix 1. In the objective function, the first priority is to achieve a goal of supplying the finished product as required at various demand destinations. This is attempted by utilizing the different types of productive resources (e.g., labor, materials, and utilities) at an optimum level. By satisfying resource usage requirements, supply/demand requirements and finished product requirements, the basic production requirements necessary to justify the new plant in the first place are satisfied. The fist priority seeks to minimize the deviation from these goals and insure that the basic production problem has been fully achieved before consideration of other subsequent goals.

The second priority seeks to obtain further cost minimizing conversions between productive resources. By including both of the deviational variables 
in the objective function, as we did for the food processing problem, we seek an exact balance of resource usage defined by $c_{k^{\prime}}^{c}$. In other words, we use conversion constraints to obtain a solution that reflects greater resource efficiency and less resource inefficiency.

The priorities $P_{3}$ through $P_{6}$ attempt to minimize the costs of various resources utilized at different plants. In each of the resources cost areas, the budgeted amount can be optimally utilized. The actual under- or overutilization of these budgeted costs can be compared between the site locations. The ordering of the cost areas to the priorities (i. e., $\boldsymbol{P}_{3}, \boldsymbol{P}_{4}, \boldsymbol{P}_{5}$, and $\boldsymbol{P}_{6}$ ) may alter the resulting allocations and costs. This provides a decision-maker with an opportunity to perform a sensitivity analysis if the decision environment permits its applicability. Such ordering, via the priority levels, may allow fuller satisfaction of some goals (e. g., labor costs) over others (e. g., utilities . costs).

\section{APPLICATION SOLUTION}

Having finished the formulation, the goal programming models for each site were run on an IBM 360/65. Both site location models contained a total of 48 variables (defined on Table I). Site $A$ contained 50 goal constraints while Site $B$ required only 40 . The resulting optimal values for both site locations model variables were presented on Table I. The resulting values clearly show that resource conversions have taken place. One conversion was between skilled and unskilled laborers. Even though the total number of laborers to be used at Site $A$ is less than that required at Site $B$, Site $A$ uses more unskilled laborers than Site $B$.

Other conversions of resources were between material usage and unskilled laborers. Since the material requirements for Site $A$ are greater than Site $B$, this increased the usage of unskilled labor by Site $A$ in the optimal solution.

The lack of unique constraints between the sites in the use of utilities and transportation, resulted in the same optimal values for both sites.

The priority analysis information presented on Table II, provides the specific information necessary to aid in the site location decision. As long as $P_{1}$ is fully satisfied the resulting solution is meaningful. Otherwise, the differing sites would not be comparing the same basic production plant facility. There is little informational value in $P_{2}$. The priorities $P_{3}$ to $P_{6}$ represent the dollar under- and overachievement in budgeted estimates. At $P_{3}$, a significant reduction in budgeted labor costs is possible if Site $A$ is selected while a small increase over budgeted labor costs will be incurred if Site $B$ is selected. At 
$P_{4}$, the opposite of $P_{3}$ is true on a much reduced basis for materials. The $P_{5}$ priority shows an equal reduction in budgeted utilities costs at either site. At $P_{6}$ the resulting minimized transportation allocation is equally over-budget by $\$ 4,510$ at either site.

These dollar cost values are added (or subtracted) together to be used to make a final decision on which site location to select. The weekly information provided by the models can now be combined with other cost data previously excluded (e. g., cost of land) to make the site location decision. For the food processor example, let's say all other costs are equal. Then the overwhelming reduction in labor costs relative to the other cost increase, makes Site $A$ the most cost efficient and desirable.

Having made the decision on the site location problem, the informational value of the goal programming model's solution continues. The variables used in the model for the selected site location, provided much of the information needed to plan the production/operations management aspects of the new plant. Such information as the number of laborers by skill and category, the required materials to be used to meet weekly production, the required weekly utility needs and a transportation schedule for finished products between the new network of plant/warehouses. This type of aggregate production and planning information is usually obtained by additional analysis using the numerous models available $[1,3,10]$. The goal programming model presented in this paper though, saves this additional step.

\section{SUMMARY}

This paper has presented the formulation and analysis of a goal programming model as an aid in selecting a facility location site. The model presented belongs to a family of goal programming models. Specifically, this model has been provided as a means by which productive resource trade-offs between different site locations can be included in the facility location analysis. The results of the model application have shown that the goal programming model can improve the site selection process by allowing simultaneous consideration of resource trade-offs.

\section{REFERENCES}

1. A. M. Dunsmuir, A Simple Allocation Algorithm in Production Planning, Journal of the Operational Research Society, Vol. 29, 1978, pp. 443-448.

2. R. L. Francis and J. A. White, Facility Layout and Location: An Analytical Approach., Prentice-Hall, Inc., Englewood Cliffs, N.J., 1974. 
3. D. A. Goodman, Goal Programming Approach to Aggregate Planning of Production and Work Force, Management Science, Vol. 20, 1974, pp. 1569-1575.

4. N. K. KwaK and M. J. Schniederjans, A Goal Programming Model for Improving Transportation Problem Solving, OMEGA, Vol. 7, 1979, pp. 367-370.

5. S. M. LeE, G. I. Green and G. S. Kim, A Multiple Criteria Model for the LocationAllocation Problem, Computers and Operations Research, Vol. 8, 1981, pp. 1-9.

6. S. M. Lee and L. S. Franz, Optimizing the Location-Allocation Problem with Multiple Objectives, International Journal of Physical Distribution and Materials Management, Vol. 9, 1979, pp. 245-255.

7. G. T. Ross and R. M. Soland, Modeling Facility Location Problem as Generalized Assignment Problems, Management Science, Vol. 24, 1977, pp. 345-357.

8. M. J. Schniederjans, N. K. Kwak and M. C. Helmer, An Application of Goal Programming to Resolve a Site Location Problem, Interfaces, Vol. 12, 1982, pp. 6572.

9. P. J. Slater, On Locating a Facility to Service Areas Within a Network, Operations Research, Vol. 29, 1981, pp. 523-531.

10. R. S. Stanton, Production Scheduling with Multiple Criteria Objective, Operational Research Quartely, Vol. 28, 1977, pp. 285-292.

\section{APPENDIX 1}

GENERALIZED GOAL PROGRAMMING MODEL FOR FACILITY LOCATION ANALYSIS

Minimize:

$$
\begin{aligned}
& Z=p_{1}\left\{\sum_{k=1}^{K}\left(d_{k}^{\rho^{-}}+d_{k}^{\rho^{+}}\right)\right.+\sum_{i=1}^{m}\left(d_{i}^{S-}+d_{i}^{S+}\right) \\
&\left.+\sum_{j=1}^{n}\left(d_{j}^{D-}+d_{j}^{D+}\right)+\sum_{\alpha=1}^{A}\left(d_{\alpha}^{n-}+d_{\alpha}^{n+}\right)\right\} \\
&+P_{2} \sum_{k=1}^{K}\left(d_{k}^{c-}+d_{k}^{c+}\right)+\sum_{g=3}^{5} P_{g} d^{B(\rho)-}+P_{6} \sum_{i=1}^{m} d_{i}^{T+}
\end{aligned}
$$

subject to:

[Resource Usage Requirements]:

$$
\begin{aligned}
& x_{k}^{\rho}+d_{k}^{\rho^{-}}-d_{k}^{\rho^{+}}=b_{k}^{\rho} ; \quad k=1,2, \ldots, K \text { and } \rho=L, M, U, \\
& \sum_{k=1}^{K} x_{k}^{\rho}+d^{\rho-}-d^{\rho-}-d^{\rho+}=b^{\rho} ; \quad \rho=L, M, U .
\end{aligned}
$$

R.A.I.R.O. Recherche opérationnelle/Operations Research 
[Supply/Demand Requirements]:

$$
\begin{array}{ll}
\sum_{j=1}^{n} x_{i j}^{S}+d_{i}^{S-}-d_{i}^{S+}=\hat{b}_{i}^{S} ; & i=1,2, \ldots, m, \\
\sum_{i=1}^{m} x_{i j}^{D}+d_{j}^{D-}-d_{j}^{D+}=\hat{b}_{j}^{D} ; & j=1,2, \ldots, n .
\end{array}
$$

[Finished Product Requirements]:

$$
\sum_{k=1}^{K}\left(r_{k}^{L} x_{k}^{L}+r_{k}^{M} x_{k}^{M}+r_{k}^{U} x_{K}^{U}\right)+d_{\alpha}^{n-}-d_{\alpha}^{n+}=b_{\alpha}^{\pi ;} \quad \alpha=1,2, \ldots, A .
$$

[Conversion of Resources]:

$$
\left(x_{k}^{p}-c_{k^{\prime}}^{c} x_{k^{\prime}}^{p}\right)+d_{k}^{c-}-d_{k}^{c+}=0 ; \quad k=1,2, \ldots, K \quad \text { and } \quad k^{\prime} \in K .
$$

[Minimization of Resources Costs):

$$
\sum_{k=1}^{K} C_{k}^{\rho} x_{k}^{\rho}+d_{g}^{B(\rho)-}-d_{g}^{B(\rho)+}=B^{\rho} ; \quad \rho=L, M, U \text { and } g=3,4,5 .
$$

[Cost Minimization of Transportation]

$$
\sum_{j=1}^{n} C_{i j}^{T} x_{i j}^{S}+d_{i}^{T-}-d_{i}^{T+}=B_{i}^{T} ; \quad i=1,2, \ldots, m,
$$

and $x, d^{-}, d^{+}, \geqq 0$.

Variables

$x_{k}^{p}$,

amount of $k$-th type of resource $\rho$ required per period where $\rho=$ labor $(L)$, materials $(M)$, and utilities $(U)$; i. e., $x^{\rho}$ may be $x^{L}, x^{M}$, or $x^{U}$

$x_{i j}^{S}, x_{i j}^{D}, \quad$ amount of finished products to be transported from $i$-th supply source to $j$-th demand destination per period to utilize (satisfy) supply (demand) requirements;

$d_{\alpha}^{\pi-}, d_{\alpha}^{\pi+}, \quad$ deviational variables representing under- and overproduction of $\alpha$-th product;

$d_{i}^{S-}, d_{i}^{S+}, \quad$ deviational variables representing under- and oversupply of finished products at $i$-th supply source;

$d_{i}^{T-}, d_{i}^{T+}, \quad$ deviational variables representing under- and overutilization of budgeted transportation cost; 
$d_{j}^{D-}, d_{j}^{D+}, \quad$ deviational variables representing the amount of finished product under- and overutilized at $j$-th demand destination;

$d_{k}^{c-}, d_{k}^{c+} \quad$ deviational variables representing under- and overachievement in the conversion of $k$-th type of substitutable resources;

$d_{k}^{\rho-}, d_{k}^{p+}, \quad$ deviational variables representing under- and overutilization of $k$-th type of resource $\rho$ [where $\rho=$ labor $(L)$, materials $(M)$, and utilities $(U)$;

$d^{B(\rho)-}, \quad$ a deviational variables representing underutilization of budget amount in resource costs (where $\rho=L, M$, and $U$ ).

Constant

$b_{k}^{\mathrm{\rho}}$

minimum amount of resource $\rho$ to be used per period for each $k$-th type of resource (where $\rho=L, M$, and $U$ );

$b^{\rho}, \quad$ maximum amount of resource $\rho$ to be used per period (where $\rho=L, M$, and $U$ );

$B^{\rho}, \quad$ (total budget dollars for all resources $(\rho=L, M$, and $U$ );

$B_{i}^{T}$,

$b_{\alpha}^{\pi}$

$\hat{b}_{i}^{S}, b_{j}^{D}$, total budgeted transportation cost at $i$-th source; required production amount of each $\alpha$-th product; estimated supply (demand) of finished products available (required) at $i$-th supply source ( $j$-th demand destination);

$c_{k^{\prime}}^{c}$ coefficient of productivity between ( $r$-th type of) substitutable resources;

$C_{i j}^{T}, \quad$ cost of transporting one unit of finished product from $i$-th supply source to $j$-th demand destination;

$C_{k}^{p}$,

$P$, unit cost for each $k$-th type of resource $(\rho=L, M$, and $U)$; priority;

$r_{k}^{p}$ proportional amount of each $k$-th type of resource used to produce one unit of finished product (where $\rho=L, M$, and $U$ ). 